\title{
Conceptual Design of a Smart Parking Lot System for Electric and Hybrid Electric Vehicles
}

\author{
K. Erhan, M. Ayaz, and Y. Icer
}

\begin{abstract}
Today, demand to electric and hybrid electric vehicles (EVs, HEVs) increases day by day due to both environmental factors and limited fossil fuel resources. With EVs and HEVs becoming widespread, some basic problems arise. One of the most important of these problems is that the users who want to charge their vehicles cause to over load on the power grid. Another problem is that charging stations are not widespread and charging station installation cost is high. This study deals with the design of a smart parking lot system that can provide collective charging services for electric and hybrid electric vehicles. In the proposed smart parking system, online booking assistance is provided and the location of charging stations is marked on the navigation so that users of EVs and HEVs can easily access the charging stations. Also, users via the designed mobile application can follow up and control booking inquiry, battery charge status, battery sharing permission and payment services. Another important feature provided by the proposed parking system is that the problem of excessive and irregular load to the power grid occurred during charging of vehicles located in the parking lot solve with the developed energy management algorithm. In the developed energy management algorithm, in case of the over loading of the power grid, the energy requirement for charging is provided from other vehicles for which prior permission for battery sharing has been obtained instead of the power grid. Thus, overloading of the power grid is prevented and, also drivers who give permission for battery sharing can derive a profit.
\end{abstract}

Index Terms-Electric vehicle, plug-in hybrid electric vehicle, charge station, smart parking lot system, energy management.

\section{INTRODUCTION}

$\mathrm{I}^{\mathrm{T}}$ $\mathrm{T}$ is envisaged that fossil fuel resources will be consumed away within 30-40 years. A study supporting this predicts that the oil will deplete in 2057 [1]. For this reason, research on electric and hybrid electric vehicles (EVs and HEVs) continues with an increasing rate. Usage of EVs and HEVs instead of only fossil fuel-based vehicles will significantly reduce both environmental pollution and dependence on oil.

K. ERHAN, is with Department of Energy Systems Engineering University of Kocaeli, Kocaeli, Turkey, (e-mail: koray.erhan@kocaeli.edu.tr)

M. AYAZ, is with Department of Electric and Energy University of Kocaeli, Kocaeli, Turkey, (e-mail: murat.ayaz@kocaeli.edu.tr)

Y. ICER, is with Department of Energy Systems Engineering University of Kocaeli, Kocaeli, Turkey, (e-mail: yusuf.icer92@gmail.com)

Manuscript received September 13, 2017; accepted January 08, 2018. DOI: $10.17694 /$ bajece.410230
According to the values published by a manufacturer, EVs have a high efficiency of $88 \%$, while the efficiency is $30 \%$ for vehicles having internal combustion engine. Furthermore, the maximum torque can be achieved in large speed range in EVs compared with conventional vehicles [2]. In this context, the widespread usage of electric vehicles will increase driving comfort. Despite all these positive developments, EVs have not reached widespread use at the desired level in our country. The main reason for this situation is that sufficient number of charging stations have not been established yet. This causes that users of EVs worry about being stranded on the road [3]. The fuel tank of conventional vehicles can be filled with fuel in very short time as approximately 3-4 minutes and depending on fuel tank capacity, about $600-1200 \mathrm{~km}$ distance can be driven with a fully loaded tank. On the other hand, users of EVs and HEVs to drive $150 \mathrm{~km}$ distance need to an average of 6-8 hours on a standard charge, or a minimum of half an hour on a quick charge. Several R\&D studies are being carried out on battery technologies to solve this problem. A vehicle manufacturer company introduced an electric vehicle battery capable with a $480 \mathrm{~km}$ driving range that could reach $100 \%$ capacity in 5 minutes [4].

Users who want to charge their vehicles at the time when the power grid is overloaded will cause the power grid to load even more. This causes some problems on the power grid such as distribution fault, power interruption and poor power quality [5]. Issues such as reservation, location information and battery sharing are being studied to solve these problems. With the reservation option, the users are able to charge vehicles by going to the pre-booked charging station and avoid the stress of finding the right charging station. Also, with location support option, users who want to charge their vehicles can find the nearest charging station that the program directs them instead of searching for a charging station. In addition of these features, extra overloading situation occurred on the power grid due to the charging process of the vehicles can be solved with battery sharing in the afternoon and evening hours when the power grid is overloaded. At times when the power grid is overloaded, energy is transferred to vehicles having empty battery from vehicles having fully charged battery. Thus, the power grid is not overloaded and power demand is balanced [6].

In this study, a smart parking automation system consisting 
of several features such as reservation, location information and battery sharing permission allows the vehicles to fill their batteries without overloading the power grid while parked. The proposed smart park automation system is recommended for places such as hospitals and airports where power interruption can cause major problems. By applied the proposed system to the vehicle parks of these enterprises, in case of energy interruption, energy supply can be provided using batteries of EVs and HEVs. In such a case, the vehicles in the vehicle park constitute an important backup energy source.

\section{ELECTRIC AND HYBRID ELECTRIC VEHICLES}

Electric vehicles take their energy from the batteries and have no other energy sources. Fully electric vehicles do not have fuel tank, internal combustion engine and generator units. Electric vehicles consist of an electric motor that provide mechanical power to traction system of the vehicle, a driver that drives the motor, and a battery group that supplies energy to the entire system. The battery group needs to be charged when the energy is consumed. Figure 1 shows the structure of the electric vehicle.

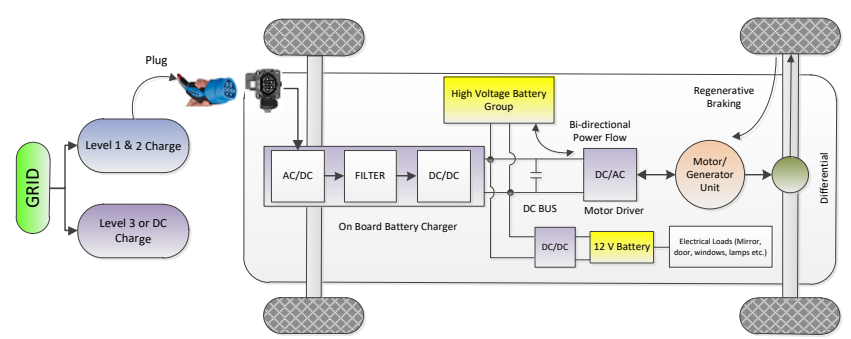

Fig.1. General structure and system components of the electric vehicle

Hybrid electric vehicles have more than one energy source. HEVs are subdivided into four classes according to the driving range [7]. These are summarized as following.

- Micro hybrid vehicles are the simplest hybrid electric vehicles. In case of starting movement of the vehicle, the electric motor provides mechanical power to traction system in urban traffic. Also, these HEVs have start-stop feature.

- Mild hybrid vehicles provide energy gain by stopping internal combustion engine when necessary. These types of vehicles can store energies that occur during braking (regenerative braking). When necessary, the electric motor provides mechanical power for traction in order to support internal combustion engine and vehicle performance can be improved. The ratio of electric motor to the total vehicle power is between $10 \%$ and $30 \%$.

- The difference between Full Hybrid vehicles and the mild hybrid vehicles is that they can only be driven using the electric motor. Except for this, they have same features of mild HEVs. The power ratio of the electric motor to the total power of vehicle is $30 \%$ or more.

- The plug-in HEVs have all the features of the other HEVs. Apart from these features, the plug-in HEVs can be charged from the power grid.
The general structure of the hybrid electric vehicle is shown in Figure 2.

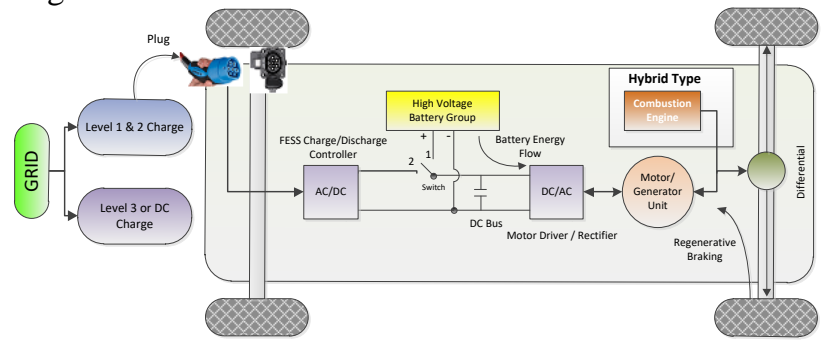

Fig.2. General structure and system components of a hybrid electric vehicle

It is stated that electric and hybrid electric vehicles will replace conventional vehicles in the near future. In this respect, various standards related to EVs and HEVs are put forward by many international institutions. Many of these standards relate to the equipment and procedures of chargers [8]. Japan adopts the CHADEMO standard and can deliver energy to vehicles up to $62.5 \mathrm{~kW}$ with direct current [9]. The IEC 62196 standard accepted in Europe can transfer energy up to $43.5 \mathrm{~kW}$ with 3-phase alternating voltage [10]. The USA allows the AC charging up to $19.2 \mathrm{~kW}$ with the SAE J1772 standard [11]. Society of Automotive Engineers (SAE) has developed SAE J-1772 and SAE J-1773 standards for conductive and inductive connection respectively. In SAE standards, 3 different power levels are defined for chargers. Level $1(120 \mathrm{~V}-15 \mathrm{~A})$ is at $1.5 \mathrm{~kW}$ of power and is the recommended power level for emergencies. These chargers are used when level 2 chargers are unavailable. These types of chargers are lightweight, cheap and portable. They can charge the vehicle battery in $10-15$ hours. Level 2 (230V-40A) charging system is at $6.6 \mathrm{~kW}$ power and is the recommended power level for nominal charging. This level is suitable for home and commercial chargers. Depending on the battery type, they can charge the battery in 3-8 hours. Level 3 is in the $25-160 \mathrm{~kW}$ range and contains large and heavy power electronics equipment. For this reason, electronic equipment is located in the station and provides DC charging. These devices capable of rapid charging within minutes can be thought of as petrol stations for EVs and HEVs [12, 13]. Expert personnel are required for the usage of Level 3 charger [14].

\section{DESIGN OF SMART PARKING SYSTEM}

The goals of the designed intelligent parking system are follows: the integration of EVs and HEVs into the power grid, elimination the extra waiting time for the battery charging, easily finding and reservation of the charging station, and preventing overloading of the power grid with battery sharing. Furthermore, batteries of vehicles can be used as a backup energy source in places such as hospitals and airports where energy interruptions cause major problems in emergencies. Today, with a standard charge (level 1-2), the required battery charge time for a $150 \mathrm{~km}$ driving range is 6-8 hours on average. A quick charge (level 3) requires a half hour of charging time to provide the same driving range. This long charging time is an important problem for users of EVs and HEVs in terms of the efficient use of the vehicle. Vehicles wait in park for an average of 22 to 23 hours per day $[15,16]$. 
In the developed system, vehicles are charged while waiting in the parking lot, so there is not any extra waiting time for charging. This is made by communicating the vehicles with the smart parking management system.

One of the most important advantages of the system is the possibility of battery sharing. On this point, users do not increase the power grid load by charging their vehicles except for the hours when the power grid is overloaded (hours when the energy is expensive). In case of necessary or preference, users whose vehicle battery is fully charged can deliver energy to the power grid or the other users. Thus, they can derive a profit.

A daily energy distribution graph recorded on 11/01/2018 In Turkey is shown in Figure 3. It is seen that the consumption of electricity in the graph is maximum between 9.00-11.00 hours and between 14.00-15.00 hours. At these times, it is not desirable that additional energy is drawn from the power grid in order to prevent overloading of the power grid. This high energy consumption during daytime hours will increase in the event of charging of electric vehicles, these unbalanced load profiles will increase costs and reduce the quality of the power.

Transient regime, short-time voltage fluctuations, long-term voltage fluctuations, interruptions, voltage fluctuations (flicker), frequency fluctuations and harmonics are events that degrade the quality of the power. These can be attributed to nonlinear loads, conveyor applications, train drivers, large motors, arc induction furnaces, sudden load changes, lightning, switching events, failures. The power quality disruption caused by the non-linear load will increase further as the EVs and HEVs are charged. This problem can be minimized, if EVs and HEVs are charged during night hours when electricity consumption is low. Also, the temperature of the distribution transformers increases with the unbalanced load profiles caused by the switching power supplies. As the value of power drawn from the transformer decreases, its temperature decreases to normal levels. The service life is shortened due to the mechanical wear caused by this temperature change in the transformer.

Users who want to charge their vehicles at times when electric power is sorely demanded may prefer to use energy obtained from the battery sharing option provided by other users in the smart parking system. With this option, extra load to the power grid can be avoided and users who give permission to the battery sharing can get a profit. In this case, the energy is not drawn from the power grid and is transferred between the vehicles. Thus, the energy consumption versus to the hours shown in Figure 3 can be balanced as shown in Figure 4.

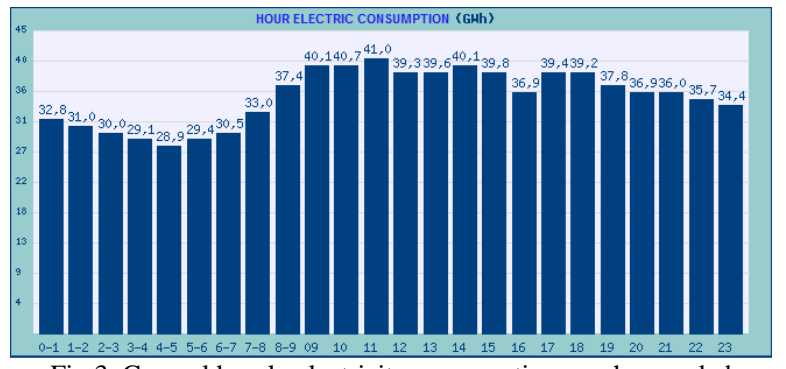

Fig.3. General hourly electricity consumption graph recorded on 11/01/2018 in Turkey (GWh) [17].

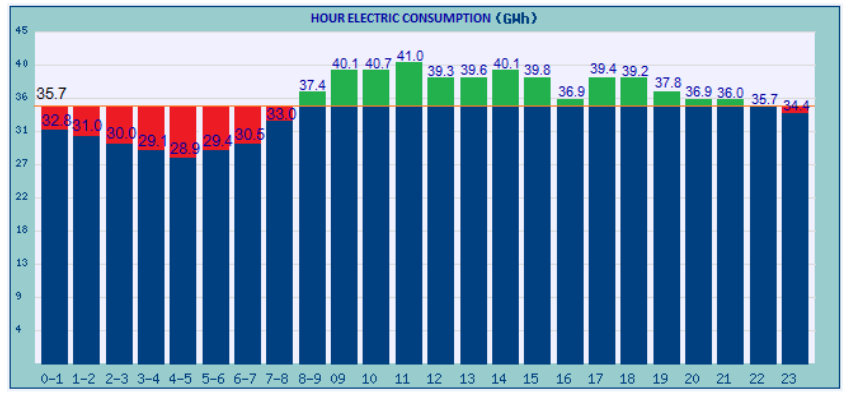

Fig.4. Balanced energy consumption graph using vehicle batteries for the day of 11.01.2018 [17].

Electric vehicle batteries can be charged by the power grid at times of low consumption. In the hours when energy demand on the power grid is above the average value, this excess demand can be supplied by electric vehicle batteries. Thus, the 24-hour energy demand can be held on average value.

\section{A. Mobile application design for the proposed system}

It is an important problem that charging of the vehicles causes overloading in the power grid. With smart parking system designed for EVs and HEVs, overloading of the power grid is prevented by the automation system capable with energy management during the charging of vehicles. The designed smart vehicle parking lot system has 16 vehicles capacity and 8 charge stations. With the developed interface software, the users are guided and it is expected that the charging procedure desired by each user will be set into the program. The mobile application has been designed with several features such as reservation, location of the closest parking lot, battery charge status monitoring, and battery sharing for deriving a profit and etc. Mobile application screens of the proposed smart parking lot system are shown in Figure 5.

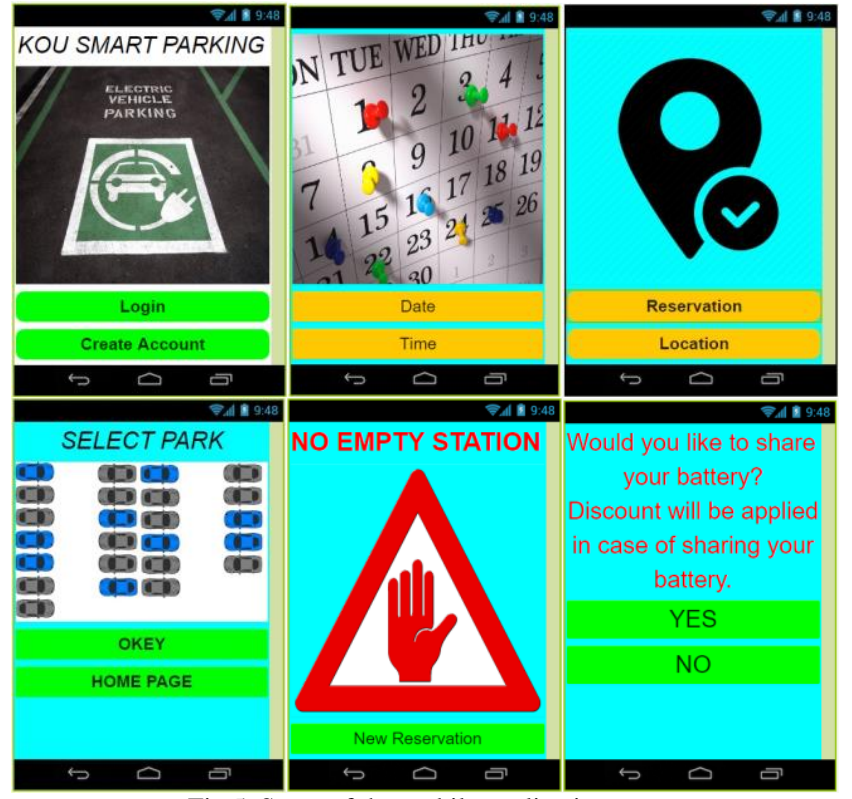

Fig.5. Some of the mobile application screens

Users often prefer vehicle park lots near their offices or residences to park their vehicles. This preference will not change even if fossil-fueled vehicles are replaced by electric and hybrid electric vehicles. However, EVs and HEVs need to 
be charged different from conventional vehicles. This situation should not prevent the efficient usage of the vehicles. If the users can charge their vehicles during parked, there will be no extra waiting time for charging. Thus, the usage efficiency of vehicle is not reduced.

Users who want to charge their vehicles using this system need to create an account first through the mobile application. After the account creation process, the users can perform the booking process for parking and charging the vehicle by detecting the parking lot closest to them. When making a reservation through the mobile application, the user is asked whether request charging, permission for battery sharing as well as the vehicle model, the date and time information. Thus, the users make reservation by giving the necessary information beforehand, without having to come to the parking lot. In addition, the users who have parked the vehicles for charging will be able to monitor the charge status of the vehicles and the battery state of charge online via the application. The consumption values of the vehicles and the payment amounts can be updated instantly and displayed on the system. If necessary, the user will be able to cut charging process online.

An energy management is carried out taking into consideration the reservation and battery sharing information, which is made on a daily and hourly basis. The required energy for the users who make the charging reservation at time when overloading of power grid will be supplied from the vehicles of the users who give permission for battery sharing. Furthermore, in case of extreme power demand, battery sharing offer is asked to all drivers of vehicles fully charged which will be waiting for long periods in the parking lot. The users who are allowed to share the battery are provided with discounts at a considerable rate. Thus, the battery sharing is encouraged.

\section{B. Automation System of Smart Parking Lot}

The block diagram of the control structure for energy management and monitoring of the proposed smart parking system is shown in Figure 6. In the system, the data of the charging stations and the energy demand values are collected and controlled by PLC. Communication network have been also established to increase the accessibility of the system among operator panel, PC and mobile application.

The priority of the developed algorithm is that perform the requested charging process on the scheduled time for all vehicles in the parking lot. However, there are many other factors to consider when providing this. While the number of vehicles dependent on electricity increases, the power grid loading factor increases with same rate. Some methods need to be developed to compensate or balance this increase such as installing new power generation plant, increasing energy efficiency, design efficient energy management systems.

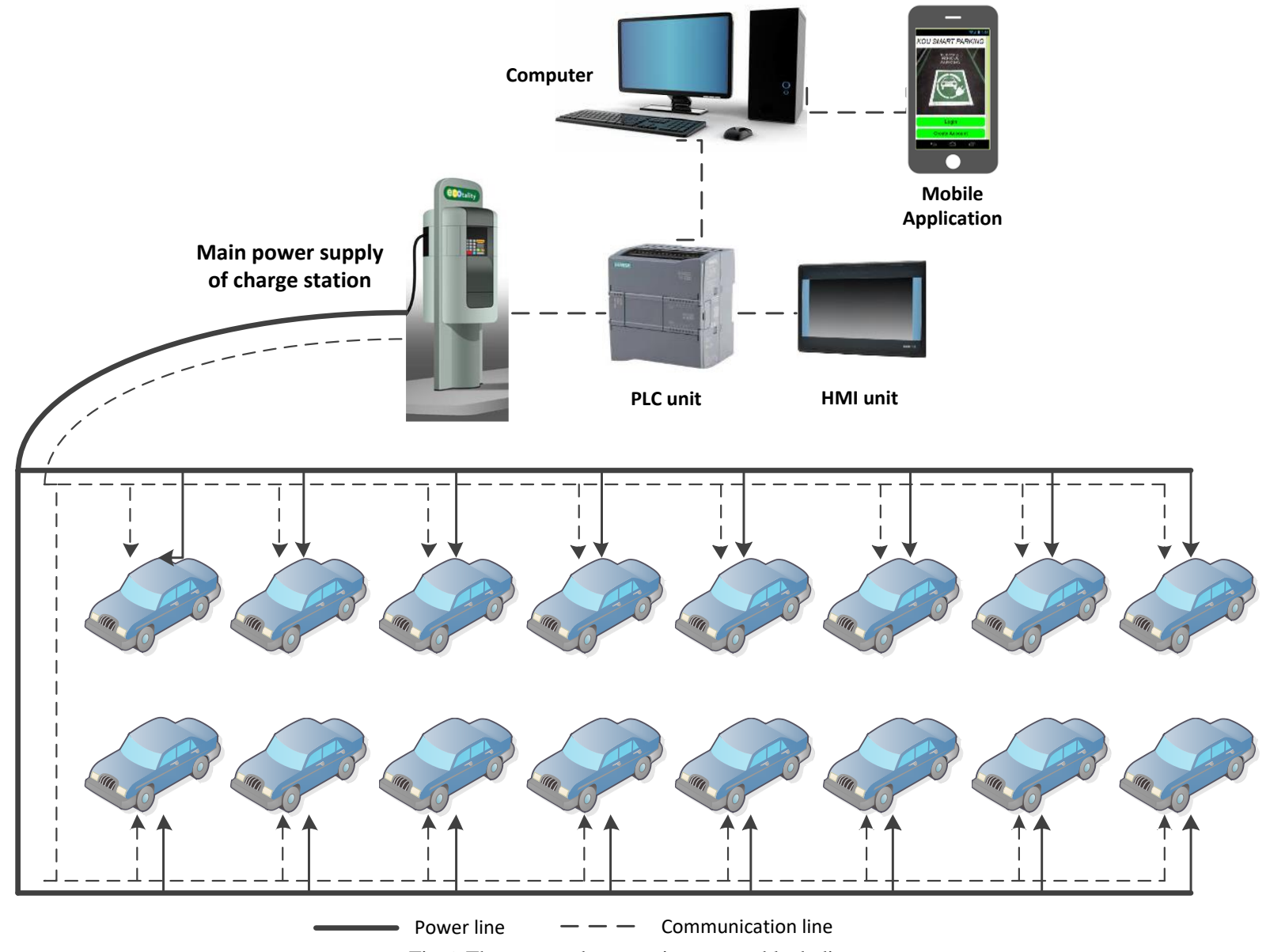

Fig.6. The proposed automation system block diagram 
The proposed system algorithm performs control of the energy management and charging schedule by considering the data obtained from the operator panel or via the mobile application. Apart from the data obtained from the application, it also evaluates the instantaneous demand situation of the power grid. In this way, it is decided how and which source that the energy required to charge vehicles will be supplied. In addition, state of charge of the vehicle battery is taken into account. The algorithm uses the battery capacities of the vehicles previously entered into the system when calculating the charging time. The proposed control algorithm of the smart parking lot system is shown in Figure 7.
First, it is checked whether a user who want to charge the vehicle has made a reservation through the mobile application. If no reservation is made, it is checked whether there is a suitable parking lot available. If no reservation is made and there is no suitable parking lot space, charging cannot be carried out. However, if there is a parking lot space, charging service can be provided.

Users are encouraged to make reservations in advance. Thus, daily energy demands can be predicted and necessary actions can be taken. If the user has made a prior reservation, parking usage and charging process can be started at the planned time.

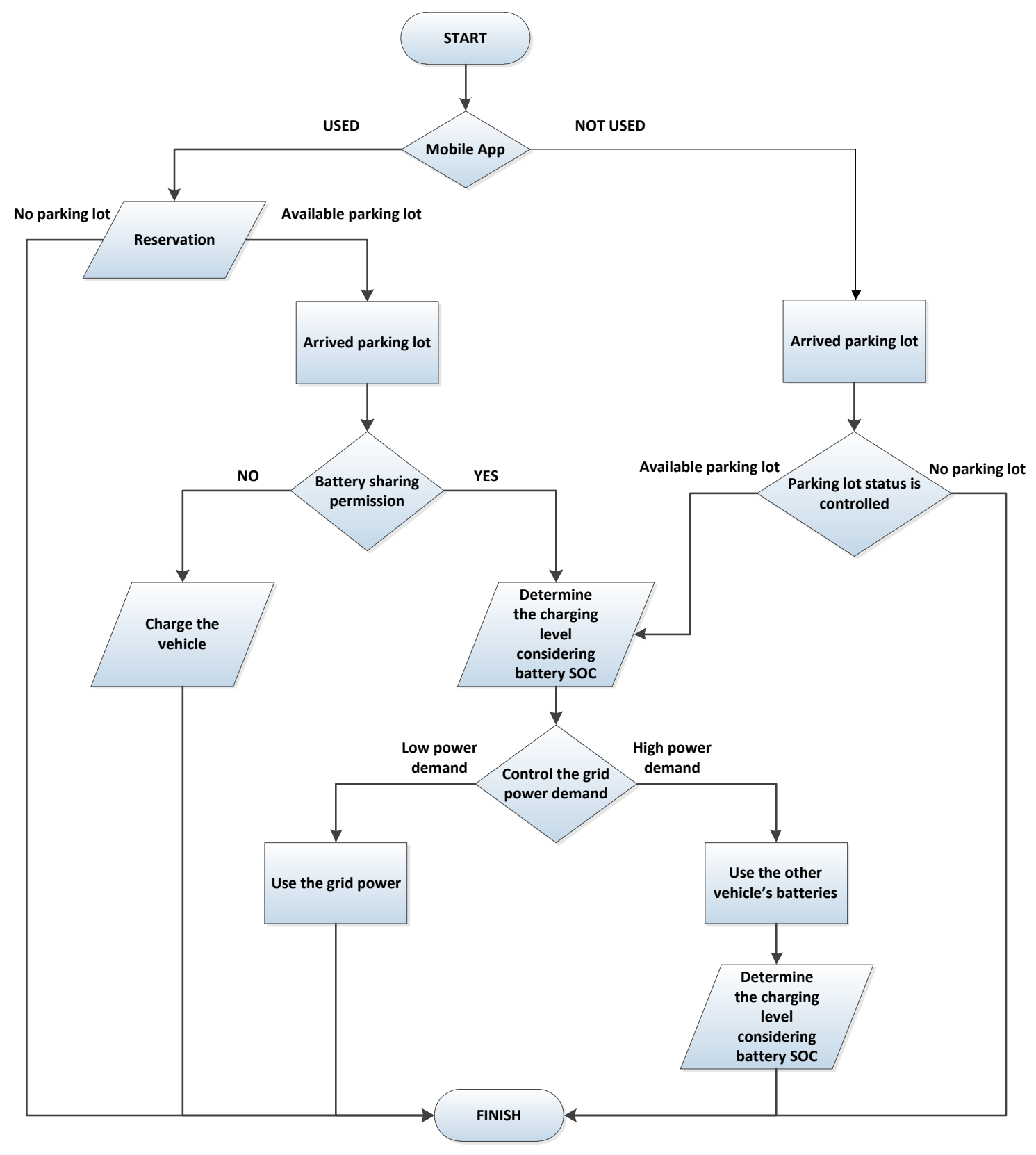

Fig.7. The proposed control algorithm of the smart parking lot system

Battery sharing approval may be given through the mobile application during or after the reservation process. If battery sharing permission is given, it ensures positive results for both the users and the power grid. Besides the users derive a profit and overloading of the power grid is prevented by means of the battery sharing option. 


\section{CONCLUSION}

The widespread usage of electric and hybrid electric vehicles will reduce environmental pollution rate and the use of fossil fuels. In addition, there will be positive results such as reduced energy costs, improved driving and comfort features. However, besides the positive aspects mentioned above, long charging time, insufficient number of charge stations, additional load on the power grid and disruption of the power quality are disadvantages emerged by using EVs and PHEVs. The proposed smart parking lot system offers solutions to some of these problems. The smart parking lot system ensures optimum power flow between vehicle battery and power grid. In the proposed system, charging service to users who want to charge their vehicles during the hours when electricity consumption reached peak value is aimed to perform without overload to the power grid. In cases of that the energy demand from power grid is high, the required energy are supplied by the battery of vehicles which is given permission to share. The more users give permission to share of the battery, the more effective balance of the power demand can be achieved. Therefore, users should be encouraged to share battery. Encouragement of users to share battery can be increased by discount of fee or providing a profit.

Referring to the hourly energy consumption in Turkey, the energy consumption changes depend on energy demands of daytime and night. By means of the proposed system, the vehicles are encouraged to be charged at night. In the daytime hours, the vehicles that are required to be charged in the parking lot are charged by using the energy in the batteries of other unused vehicles instead of the power grid. Thus, energy demand to vehicle charging from the power grid is minimized. At this point, electricity generation and distribution companies will not have to increase the energy production capacity. In addition, system components such as transformer and transmission lines are prevented to strain during peak times.

\section{ACKNOWLEDGMENT}

Koray ERHAN is supported by ASELSAN Graduate Scholarship for Turkish Academicians.

\section{REFERENCES}

[1] T.Appenzeller, End of cheap oil, National Geographic Online Magazine, 2004, Available: http://ngm.nationalgeographic. com/ngm/0406/feature5/, 01.03.2018.

[2] Y. Gürbüz, A. A. Kulaksız, "Elektrikli araçlar ile klasik içten yanmalı motorlu araçların çeşitli yönlerden karşılaştırılması", Gümüşhane Üniversitesi Fen Bilimleri Enstitüsü Dergisi, Vol.6, No.2, 2016, pp.117125.

[3] N. Andrenacci, R. Ragona, G. Valenti, "A demand-side approach to the optimal deployment of electric vehicle charging stations in metropolitan areas", Applied Energy, Vol.182, No.1, 2016, pp.39-46.

[4] https://spectrum.ieee.org/energywise/green-tech/fuel-cells/storedotwants-to-charge-your-ev-in-5-minutes, Available: 3.06.2015.

[5] S. Deilami, A. S. Masoum, P. S. Moses, M. A. S. Masoum, "Real-Time Coordination of Plug-In Electric Vehicle Charging in Smart Grids to Minimize Power Losses and Improve Voltage Profile", IEEE Transaction on smart grid, Vol.2, No.3, 2011, pp.456-467.

[6] T. Kupka, M. Patt, "Hybrid Photovoltaic Inverter for Smart Grids", Balkan journal of electrical \& computer engineering, Vol.2, No.1, 2014, pp.20-22.

[7] A. Keskin, Hibrit Taşıt Teknolojileri ve Uygulamalarl, Mühendis ve Makine, 2009, pp. 12-20.
[8] C. C. Chan, "The state of the art of electric, hybrid and fuel cell vehicles", Proceedings of the IEEE, Vol.95, No.4, pp.704-718.

[9] TEPCO (2010-03-15). "General Outline of CHAdeMOAssociation".

[10] Volker Lazzaro (2010-02-14). "The interface between the electric vehicle and infrastructure"p13.

[11] SAE Electric Vehicle Conductive Charge Coupler, SEAJ1772, Rev.Month01.

[12] N. H. Kutkut, D. M. Divan, D. W. Novotny, "Design considerations and topology selection for a 120-kW IGBT converter for EV fast charging", IEEE Transactions on Power Electronics, 1998, Vol.13, No.1, pp.169178.

[13] I. A. Khan, "Battery chargers for electric and hybrid vehicles", Power Electronics in Transportation, 1994, proceedings, pp.103-112.

[14] S. Dhameja, Electric Vehicle Battery Systems, Newnes Press, 2002, p.430.

[15] S. Yardım, "Bölgesel otopark yönetimi", 1. Kentiçi ulaşımda otopark politikaları ve uygulamaları konferans1, 2009, pp.90-107.

[16] T. Litman, Parking management best practices, American planning association, Victoria Transport Policy Institute, 2006.

[17] http://www.enerjiatlasi.com/elektrik-tuketimi/, available: 01.03.2018.

\section{BIOGRAPHIES}

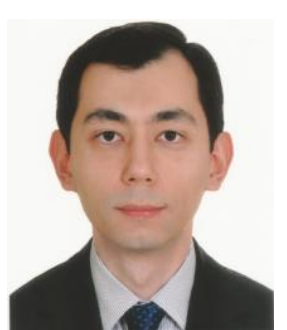

Koray ERHAN (Research Assistant) was born in 1987 in Turkey. He received his B.Sc. in Electrical Engineering from Yildiz Technical University, Turkey in 2010. Then he completed his MSc in Electrical Engineering at Istanbul Technical University in 2013. He became a Research and Teaching assistant in 2010 at Istanbul Technical University. Then he has transferred to Kocaeli University as a Research and Teaching assistant in 2013. He is already continues his $\mathrm{PhD}$ education in Energy Systems Engineering at Kocaeli University. He has published many papers in different subjects including photovoltaic power generation systems, renewable energy sources, energy storage technologies, smart grid integration, automation systems and electrical, hybrid electrical vehicles. He has been a referee in SCI and other indexed journals. He is currently holding position of research assistant at Kocaeli University.

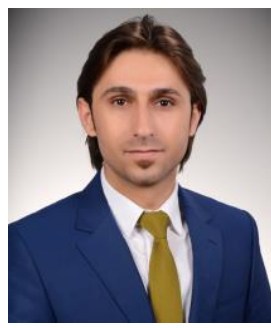

Murat AYAZ received his B.S., M.S., and Ph.D. degrees from the Department of Electrical Education, Kocaeli University, Kocaeli, Turkey, in 2005, 2008, and 2015, respectively. Between 2005 and 2009, he worked as a project engineer in Beck \& Pollitzer, Kocaeli, Turkey. From 2009 to 2015, he served as a research assistant in the Electrical Education Department of Kocaeli University, Kocaeli. Currently, he is an assistant professor at Electric and Energy Department of Kocaeli University. His current research includes design of electrical machines, hybrid electric vehicles, and industrial automation systems.

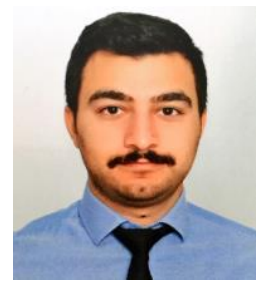

Yusuf ICER was born in 1992 in Turkey. He received his B.Sc. in Energy Systems Engineering from Kocaeli University, Turkey in 2016. He is already continues his Master education in Energy Systems Engineering at Kocaeli University. 